\title{
A new species of Dermopristis Kearn, Whittington \& Evans-Gowing, 2010 (Monogenea: Microbothriidae), with observations on associations between the gut diverticula and reproductive system and on the presence of denticles in the nasal fossae of the host Glaucostegus typus (Bennett) (Elasmobranchii: Rhinobatidae)
}

\author{
Ian D. Whittington · Graham C. Kearn \\ Received: 26 February 2011 / Accepted: 1 April 2011 \\ (C) Springer Science+Business Media B.V. 2011
}

\begin{abstract}
Dermopristis cairae n. sp. (Monogenea: Microbothriidae) is described from the skin and possibly from the nasal fossae of the giant shovelnosed ray Glaucostegus typus (Bennett). The new species is distinguished from D. paradoxus Kearn, Whittington \& Evans-Gowing, 2010 by its larger size, body shape, lack of transverse ridges on the ventral surface and absence of a seminal receptacle. Extensive short gut branches lie dorsal to the testes and adjacent to the coiled region of the vas deferens and the oötype, possibly reflecting high metabolic demand in these areas. Denticles are present in the lining of the nasal fossae of G. typus, providing a firm
\end{abstract}

I. D. Whittington ( $₫)$

Monogenean Research Laboratory, Parasitology Section, The South Australian Museum, North Terrace, Adelaide, SA 5000, Australia

e-mail: ian.whittington@samuseum.sa.gov.au

I. D. Whittington

Marine Parasitology Laboratory, School of Earth and Environmental Sciences (DX 650 418), The University of Adelaide, North Terrace, Adelaide, SA 5005, Australia

I. D. Whittington

Australian Centre for Evolutionary Biology and Biodiversity, The University of Adelaide, North Terrace, Adelaide, SA 5005, Australia

G. C. Kearn

School of Biological Sciences, University of East Anglia, Norwich NR4 7TJ, UK substrate for the cement-based attachment of a microbothriid. However, confirmation that D. cairae inhabits the nasal fossae of G. typus is required.

\section{Introduction}

Microbothriid monogeneans are typically found on the skin of elasmobranch fishes (sharks and rays), where they attach themselves to a single denticle by means of a small hookless haptor (Kearn, 1965; Whittington \& Chisholm, 2008). Denticles have no epidermal covering and their hardness precludes use of hooks for attachment. The microbothriid skin parasite Leptocotyle minor (Monticelli, 1888) Monticelli, 1905 uses cement to attach itself to a single host denticle (Kearn, 1965; Kearn et al., 2001). In June 2001, Prof. J. Caira and Dr K. Jensen collected several microbothriids during a freshwater bathing treatment of a giant shovel-nosed ray Glaucostegus typus (Bennett) (Elasmobranchii: Rhinobatidae) at Cairns Marine Aquarium Supply in Cairns, Queensland, Australia and kindly donated them to one of the authors (IDW). We identified these specimens as a new species of microbothriid, which is described herein.

An indication on the slide labels (see below) that some of these parasites might be from the nasal fossae was of special interest, because Price (1938) also claimed to have found the microbothriid Dermophthirius carcharhini MacCallum, 1926 in the 
olfactory organs (= nasal fossae) of a shark identified by Price as 'Carcharias commersonii'. There is no published information on whether nasal fossae of elasmobranchs contain denticles or other hard surfaces that may provide suitable substrates for the cement-based attachment of microbothriids. Thus we examined the inner surfaces of nasal fossae dissected from specimens of G. typus.

\section{Materials and methods}

Five monogenean specimens (four adults and one juvenile) from Glaucostegus typus were received from Prof. Caira and mounted. More information on the host specimen can be obtained by entering the unique code number JO-9 at http://web2.uconn.edu/tapeworm/ hosts.php. One of the four adult parasites was deposited as a voucher specimen, identified at the time by IDW as Dermophthirius sp., in the Australian Helminthological Collection (AHC) of the South Australian Museum (SAMA) (registration number SAMA AHC 29664) as part of a separate phylogenetic study (see Perkins et al., 2009). This specimen was obtained on loan and is included in the present study.

There is some uncertainty regarding the locations of the five monogenean specimens on the host. Notes made by Prof. Caira at the time were as follows: "one vial dorsal monogeneans in 95\% alcohol" and "one vial dorsal monogeneans in $10 \%$ formalin". The single adult voucher specimen (SAMA AHC 29664 deposited by Perkins et al., 2009) bears the inscription "ex skin denticles". However, the slide labels relating to the other three adults and the single juvenile specimen bear the inscription "ex nasal tissue??" Prof. Caira and subsequently IDW, in whose laboratory the material was mounted, are unable to determine the origin of this attribution to nasal tissue.

Freshwater treatment kills monogeneans rapidly but does not necessarily lead to detachment of the parasites. Dislodgement of the dead parasites may be required, providing an opportunity to note the precise location of the parasites on the host. However, the collectors did not record whether the dead microbothriids were physically removed from the host or collected from the bottom of the treatment tank (Prof. Caira, personal communication).
All specimens, with the exception of SAMA AHC 29664, are unstained and mounted in Canada balsam. Specimen AHC 29664 was stained with Semichon's carmine. Whole-mounts were examined using a compound microscope equipped with phase contrast optics. Measurements, made with a calibrated ocular micrometer, are presented in micrometres as the mean followed by the range in parentheses and the number of measurements taken, unless otherwise stated. Where measurements are separated by a multiplication sign, the first dimension is length followed by breadth. The boundaries of soft parts, such as testes, were sometimes obscure and, in these circumstances, the measurements are approximations.

Comparison was made with the following wholemounted museum specimens of Dermopristis paradoxus Kearn, Whittington \& Evans-Gowing, 2010, from the skin and mouth of the largetooth sawfish Pristis microdon Latham (Elasmobranchii: Pristidae): four specimens from the AHC of SAMA (one immature) (SAMA AHC 29784-29787); three specimens (one immature) from the Parasitic Worms Group, Natural History Museum, London (paratypes 5, 8 and 10 from the series BMNH 2009.10.27.1-4); one immature specimen from the United States National Parasite Collection (USNPC 102403). Reference was also made to a series of transverse resin sections (numbers 525/36-52) of an adult specimen of $D$. paradoxus in the collection of one of the authors (GCK) (see Kearn et al., 2010).

Nasal fossae were examined from two immature specimens of G. typus caught in February, 2002 at Shark Bay, Heron Island, Queensland, Australia and preserved in $10 \%$ formalin. One specimen was a male (wingspan, $13 \mathrm{~cm}$; length, $39.2 \mathrm{~cm}$ ); the other was a female (wingspan, $13 \mathrm{~cm}$; length, $38.8 \mathrm{~cm}$ ). The nasal fossae, still in situ in the head, were bisected along their long axes. This permitted examination of their internal surfaces, including the olfactory lamellae and the linings of the incurrent and excurrent passages, using incident light and a stereomicroscope.

Type-material of the new taxon is deposited in the AHC of SAMA, North Terrace, Adelaide, South Australia 5000, Australia (contact: Leslie Chisholmleslie.chisholm@samuseum.sa.gov.au).

\section{Microbothriidae Price, 1936 \\ Microbothriinae Price, 1936}




\section{Dermopristis Kearn, Whittington \& Evans-Gowing, 2010}

\section{Revised diagnosis}

Haptor small; sclerites absent. Ventral body surface with or without parallel, roughly transverse ridges. Gut dendritic. Testes 2, juxtaposed. Proximal part of vas deferens highly coiled, communicating with tubular male reproductive tract, divided into 2 distinct regions: proximal region with thick wall; distal region with highly folded wall and spacious lumen with ventral opening on left of mid-line. No readily recognisable male copulatory organ; no sclerites associated with male apparatus. Distal region of vagina narrow, opening ventrally near male opening; proximal region enlarged to form seminal receptacle or not. Female genital opening near openings of vagina and male system. Ectoparasitic on elasmobranchs.

Type-species: D. paradoxus Kearn, Whittington \& Evans-Gowing, 2010.

Other species: D. cairae n. sp.

\section{Dermopristis cairae n. sp.}

Type-host: Glaucostegus typus (Bennett) (Rhinobatidae) (giant shovel-nosed ray).

Type-locality: Origin of host uncertain, but collected by and kept at Cairns Marine (aquarium fish distributor), Cairns, Queensland, Australia.

Site: Dorsal skin and perhaps nasal fossae.

Type-material: Holotype SAMA AHC 35106 (1 adult), 3 paratypes SAMA AHC 35107 (1 adult), SAMA AHC 35108 (1 immature specimen), SAMA AHC 29664 (1 adult; formerly a voucher specimen with the same registration number from Perkins et al. (2009) previously identified as Dermophthirius sp.). The following GenBank accession numbers from Perkins et al. (2009) now apply to the new taxon described below: 28SrRNA-FJ971988; Histone 3-FJ972104; Elongation Factor $1 \alpha$-FJ972048).

Etymology: The species is named for the donor of the specimens, Prof. Janine Caira, in recognition of her prominent contributions to the systematics of parasites from sharks and rays.

\section{Description (Figs. 1-4)}

[Based on 4 adult specimens (holotype, 2 paratypes plus 1 whole-mounted adult that was subsequently unmounted, embedded in resin and sectioned serially as part of a separate study (work in progress), and 1 immature paratype mounted on slides). Dimensions based on 4 mounted adult specimens, unless stated otherwise.] Whole animal 5,934 (5,174-6,257) $3 \times 6,527(5,354-7,069)$. Greatest width in all specimens, including immature parasite, approximately at level of testes, $c .2 / 3$ of distance from anterior end of body (Fig. 1). Dimensions of whole immature parasite 2,587 $\times 2,647$. Adult haptor small (Fig. 1): outer width $c .748$ (644-813) 3, inner width (central haptor cavity) c.359 (288-438) 3. Outer and inner widths of haptor of immature parasite $c .470$ and 188 , respectively. No host denticles present in haptors of mature or immature specimens, but crumpled translucent material in haptor cavity may be cement. No parallel, roughly transverse ridges present on ventral surfaces. Mouth anterior, subterminal, leading to deeply infolded buccal cavity (Fig. 1). Eyes absent. Approximately 9 digitiform papillae project into lumen of pharynx. No gland-cells or gland-ducts observed inside papillae or in pharyngeal wall. Prominent muscles, 1 on each side, run from external surface of posterior region of pharynx in posterolateral direction (Fig. 2). Approximate pharyngeal dimensions: 572 $(470-635) \times 601(470-690)$.

Gut highly branched; contains brown pigment throughout in all specimens, including juvenile, hence gut conspicuous (Figs. 2, 3). Main gut diverticula tend to run close to routes of vitelline ducts, with extensive branching amongst vitelline follicles, except in following areas where vitelline ducts/ follicles are absent: immediately lateral to pharynx (Fig. 1); region occupied by part of reproductive system (testes, coiled vas deferens and oötype) (Fig. 2; more details below); region immediately surrounding haptor (Fig. 1). Testes 2, of equal size, juxtaposed (Figs. 1, 2); testicular dimensions: 841(625-1075) × $1036(850-1188)$ 8. Each testis almost completely encircled by gut diverticulum, which gives rise to short, highly branched, stubby diverticula covering much of dorsal surface of testis (Fig. 2).

Each testis contains numerous, unpigmented, elongate-oval or circular structures, which are possibly dorsoventral muscle columns seen in optical section. In holotype (AHC 35106), each testis gives rise to 3 narrow vasa efferentia uniting to form vas deferens (Fig. 2). Vasa efferentia identified in single 


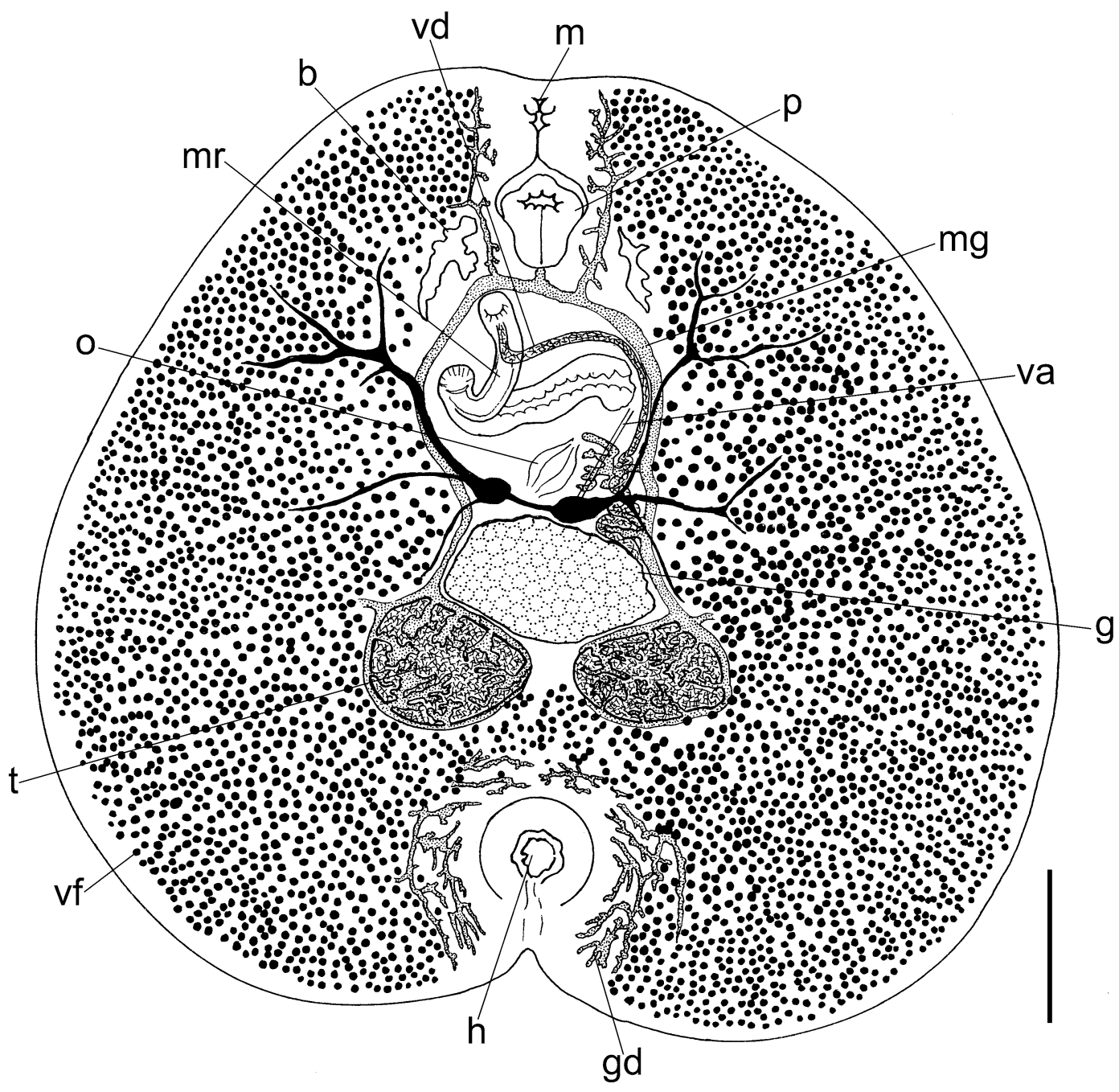

Fig. 1 Dermopristis cairae n. sp. Whole animal (composite, ventral view), showing main anatomical features (oviduct and vasa efferentia omitted for clarity). Abbreviations: b, bladder; g, germarium; gd, gut diverticulum; h, haptor; m, mouth; mg, main lateral branch of gut; mr, tubular male reproductive tract; o, oötype; p, pharynx; t, testis; va, vagina; vd, vas deferens; vf, vitelline follicle. Scale-bar: $1 \mathrm{~mm}$

other adult specimen (AHC 29664); 3 vasa efferentia from 1 testis, only 2 from other. Just anterior to germarium, vas deferens highly coiled before continuing to follow curved path to proximal end of tubular male reproductive tract (Fig. 2).

Group of short, stubby, medianly directed gut diverticula associated with highly coiled region of vas deferens and possibly also with oötype (Figs. 2, 3 ). Anteriormost of these diverticula branches repeatedly to give rise to conspicuous group of short, digitiform diverticula (Figs. 2, 3). As in adults, immature specimen with pigment-filled gut diverticula overlying testes and in region occupied by coiled vas deferens.

Tubular male reproductive tract with thick walls and spacious lumen, divided into 2 regions: proximal glandular region with roughly longitudinal orientation and distal region orientated in roughly transverse direction (Figs. 1, 2). Male opening ventral, left of mid-line (Figs. 1, 2). No readily recognisable male copulatory organ; no sclerites associated with terminal male apparatus. Fusiform capsules, likely to be 


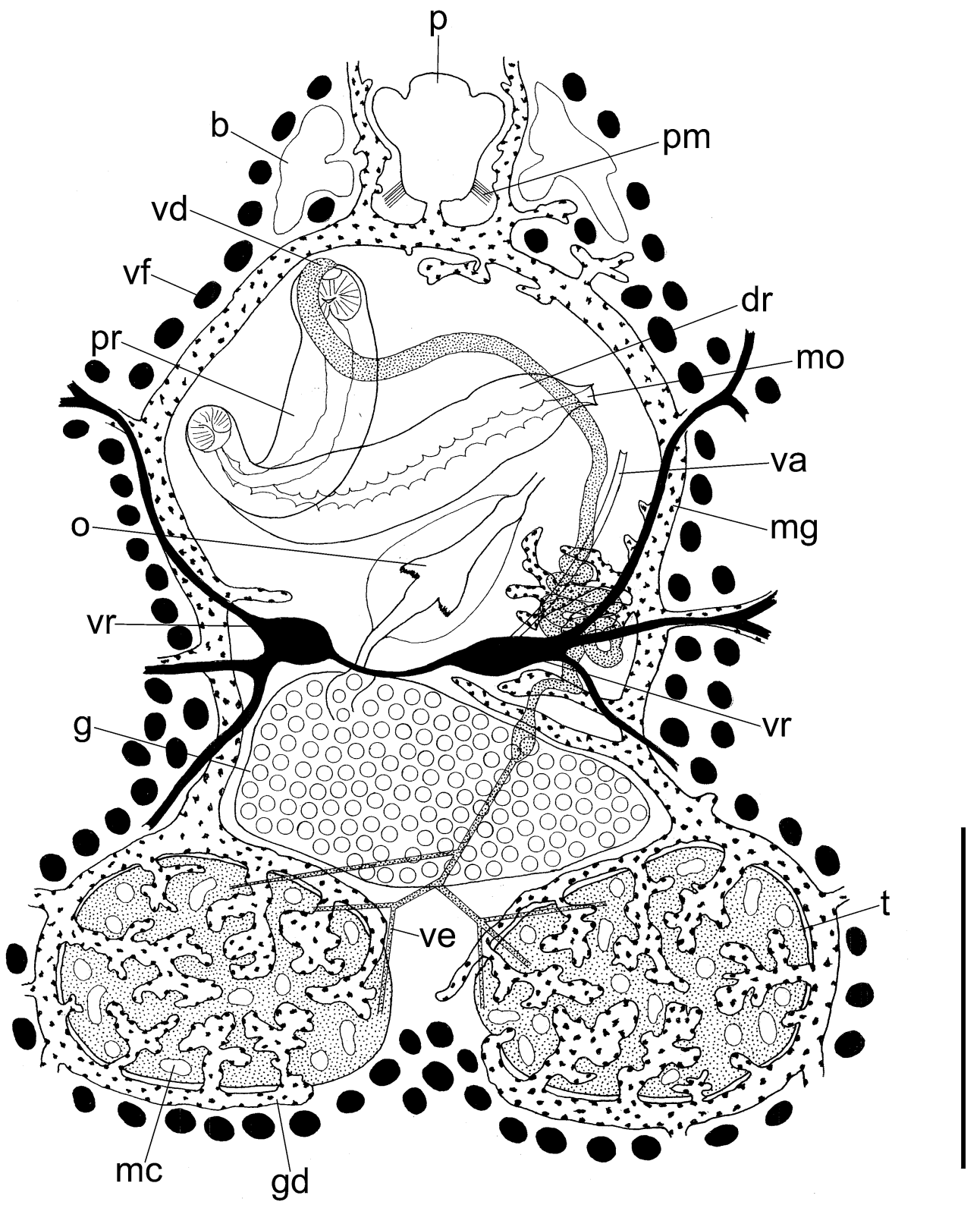

Fig. 2 Dermopristis cairae n. sp. Reproductive system and its relationship with the gut, in ventral view. Based on the holotype. Abbreviations: dr, distal tubular region of male reproductive tract; mc, muscular (?) column in testis; mo, opening of male reproductive tract; pm, pharyngeal extrinsic muscle; pr, proximal tubular region of male reproductive tract; ve, vas efferens; vr, vitelline reservoir. Other abbreviations: as in Fig. 1. Scale-bar: $1 \mathrm{~mm}$

spermatophores, 400-500 long attached by long stalks to ventral surfaces of 2 parasites. One specimen previously mounted and contributing to this description, subsequently unmounted, embedded in resin and sectioned serially (work in preparation), with 3 capsules (Fig. 4), the other (SAMA AHC 29664) with single capsule.
Vagina narrow (Fig. 2). Position of vaginal pore not identified, but vagina traced to region close to male reproductive opening. Seminal receptacle absent; vagina opens proximally into left vitelline reservoir (see below and Fig. 2). Shape of oötype indicates tetrahedral egg (Fig. 2), but eggs not observed. Position of female opening not identified, 


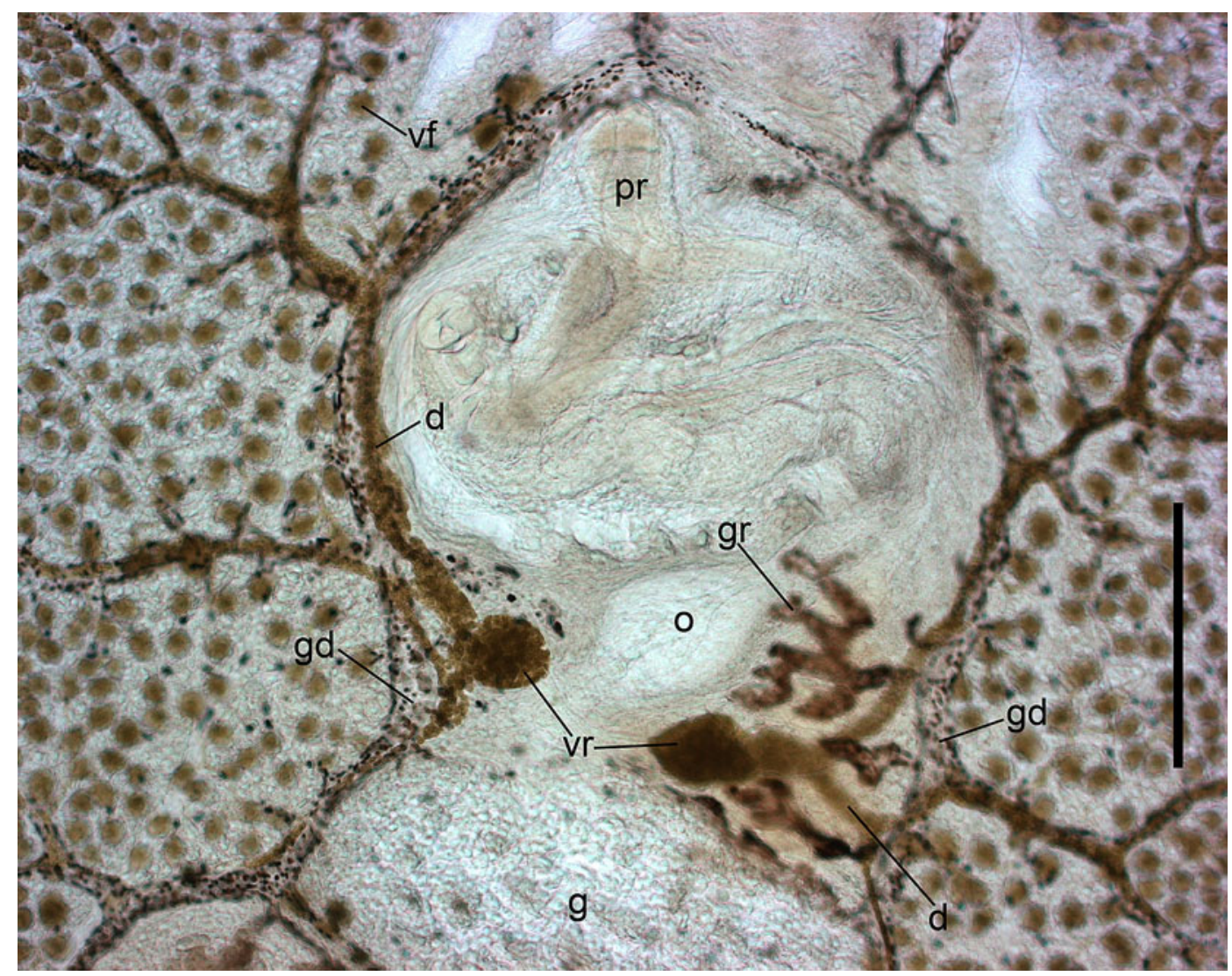

Fig. 3 Dermopristis cairae n. sp. Photomicrograph of mounted specimen in ventral view, showing gut diverticula (gd), vitelline ducts (d), and group of short, digitiform gut diverticula (gr) associated with coiled vas deferens. Other abbreviations: as in Figs. 1, 2. Scale-bar: $0.5 \mathrm{~mm}$

but anterior extent of female reproductive tract traced to region close to and posterior to male opening.

Vitelline cells stored in 2 reservoirs, 1 on each side of mid-line (Fig. 2). Vitelline reservoirs linked by transverse vitelline duct.

\section{Differential diagnosis}

The new species is distinguished from its congener, $D$. paradoxus, by its larger size, body shape (D. paradoxus is oval with a maximum width at midbody, whereas the body width of $D$. cairae $\mathrm{n}$. sp. is greater than the total length, with a maximum width approximately two-thirds of the distance from the anterior end), the absence of ventral, roughly transverse body ridges, the absence of a seminal receptacle, and the presence of highly branched gut diverticula associated with the testes, the coiled vas deferens and possibly the oötype (but see note below).
Note on gut diverticula

At first sight, the readily visible gut diverticula associated with the testes, vas deferens and oötype in all specimens of D. cairae n. sp. and the apparent absence of these special diverticula in D. paradoxus appears to be a reliable feature for distinguishing the two species. An intensive search, using bright field and phase contrast microscopy, of paratypes of D. paradoxus failed to reveal gut diverticula overlying the testes or gut diverticula associated with the coils of the vas deferens or with the oötype. Only one of the specimens of D. paradoxus (an immature individual: BMNH 2009.10.27.1, paratype 5) contained pigment in the gut (Kearn et al., 2010) and, since the presence of pigment in D. cairae renders these diverticula conspicuous, special attention was paid to this specimen, but no diverticula associated with the testes, vas deferens or oötype were visible. 


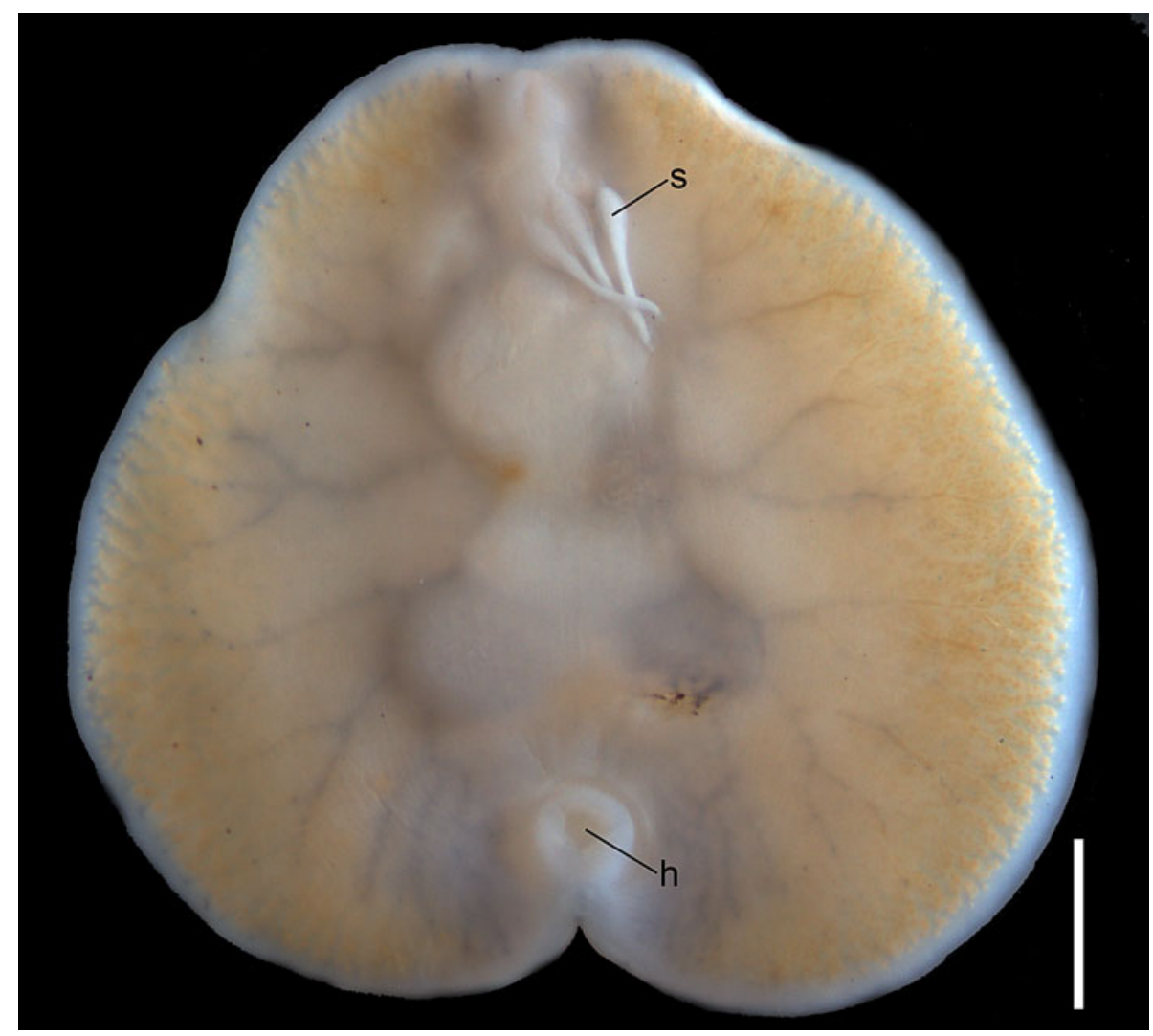

Fig. 4 Photomicrograph of Dermopristis cairae n. sp. in ventral view, showing three attached spermatophores. Same specimen, but unmounted, shown in Fig. 3. Abbreviations: h, haptor; s, spermatophore. Scale-bar: $1 \mathrm{~mm}$

However, serial resin sections (GCK 525/36-52) through an adult specimen of $D$. paradoxus revealed the presence of gut diverticula dorsal to the testes (no diverticula were found ventral to the testes). Consequently, it may be unwise to regard the special association between the gut diverticula and the testes, vas deferens and oötype as a unique feature of $D$. cairae, because the presence or absence of gut pigment and hence the visibility of this special feature in D. paradoxus and D. cairae may depend on the feeding location of the parasite and whether or not the host's skin at this site contains sufficient pigment to highlight these diverticula.

\section{Nasal fossae}

The floor of each of the nasal fossae from the two small specimens of $G$. typus was occupied by two rows of olfactory lamellae arranged side by side (Fig. 5), as described by Abel et al. (2010) in the hammerhead shark Sphyrna tudes (Valenciennes).
These lamellae are soft, flexible, resemble gill lamellae and contain or support no denticles. Two flaps located roughly midway along the nasal aperture project across this aperture and separate the incurrent and excurrent passages. One flap is relatively large and projects in an antero-lateral direction from the posterior border of the fossa, whereas the other flap is small, narrow and projects in a postero-lateral direction from the anterior border. Some areas of the inner lamellafree surfaces of each fossa are smooth and free of denticles, but there is a large area of tightly packed denticles on the inner surface of the large flap (Fig. 5) and a small area of scattered denticles on the inner surface of the fossa adjacent to the small flap. The denticle fields on the inner surfaces of the large flaps were continuous with the denticles in the ventral body skin surrounding the ventrally directed nasal apertures. The presence or absence of pigment in the lining of the fossae was not recorded.

No microbothriid monogeneans were found in the nasal fossae of these two rays off Heron Island. IDW 


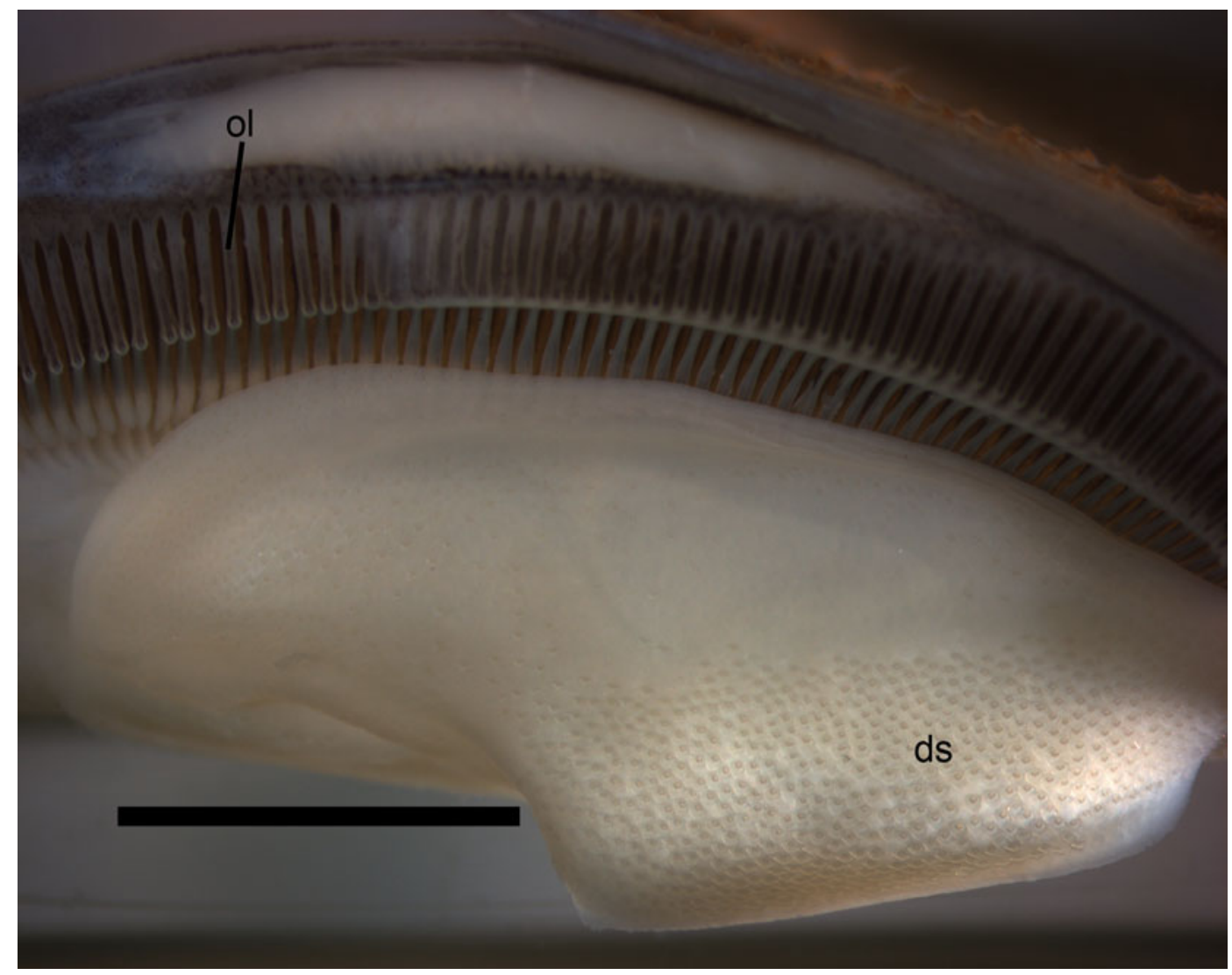

Fig. 5 Photomicrograph of exposed inner surface of a nasal fossa of Glaucostegus typus showing denticle-free olfactory lamellae (ol) and extensive field of highly packed denticles (ds) on the inner surface of a large flap that projects from the posterior border of the nasal fossa across the nasal aperture. Scale-bar: $5 \mathrm{~mm}$

(previously unpublished observation) has dissected numerous specimens of $G$. typus off Heron Island during the period 1987 to 2002 and no microbothriids have been observed either near the nasal fossae or on skin surfaces elsewhere.

\section{Discussion}

The microbothriid monogenean Dermopristis cairae n. sp. is described from the giant shovel-nosed ray Glaucostegus typus (Rhinobatidae). According to the slide labels, the parasite lives on the dorsal skin and possibly in or around the nasal fossae of the host. More precise information on its microhabitat is not available (see 'Materials and methods' and below). A congener, D. paradoxus, is a skin parasite of the largetooth sawfish Pristis microdon (Pristidae), but the new species is readily distinguished from $D$. paradoxus by its size and shape, lack of roughly transverse ventral body ridges and the absence of a seminal receptacle.

The original description of $D$. paradoxus by Kearn et al. (2010) highlighted its enigmatic reproductive system and the lack of a recognisable male copulatory organ (penis or cirrus). Kearn et al. (2010) discussed ways in which sperm transfer could be achieved, including the possibility that the parasite assembled and exchanged spermatophores. The absence of an obvious copulatory organ and the relatively spacious lumen and glandular wall of the male reproductive tract are features consistent with the assembly of spermatophores, but none was found. However, the ventral surfaces of two of the specimens of D. cairae carried structures likely to be spermatophores (Fig. 4). The notion that these 
capsules were eggs was dismissed, since they are too large to be assembled in the oötype and the shape of the oötype indicates that the eggs are tetrahedral. The close similarity between the reproductive systems of $D$. cairae and $D$. paradoxus strongly suggests that both of these parasites assemble and exchange spermatophores. The structure of these spermatophores in D. cairae and their relationship with the openings of the reproductive system will be considered separately (work in progress).

In the holotype of $D$. cairae, three vasa efferentia emerged from each testis, all six uniting to form the single vas deferens (Fig. 2). In a second adult specimen (SAMA AHC 29664) one of the two testes was drained by three vasa efferentia but only two vasa efferentia were observed emerging from the second testis. However, the vasa efferentia are difficult to resolve and a third vas efferens arising from this testis may have been obscured. This raises the possibility that $D$. cairae has evolved from an ancestor with six testes, reduced to two by testicular fusion. Testis number in microbothriids is variable. Leptocotyle minor and Pseudoleptobothrium aptychotremae Young, 1967 each have a single testis (Sproston, 1946; Glennon et al., 2006, respectively), whereas Asthenocotyle kaikourensis Robinson, 1961 is reported to have 64 (Beverley-Burton et al., 1987). A microbothriid with six testes has not been recorded. In a molecular phylogenetic analysis of the Capsalidae based on three unlinked nuclear genes by Perkins et al. (2009), four microbothriid species were included among 15 outgroup taxa. Asthenocotyle kaikourensis and Pseudoleptobothrium sp. grouped together, whereas D. cairae (as Dermophthirius sp. of Perkins et al., 2009) grouped with Dermophthirius penneri Benz, 1987, each of which possesses two testes.

The gut of all five specimens of D. cairae contains abundant brown pigment. Gut pigment was found in only one (an immature individual) of 13 specimens of D. paradoxus (see Kearn et al., 2010). The microbothriid L. minor feeds on host epidermis (Kearn, 1965) and it is likely that other microbothriids share the same diet. The epidermis of the dogfish Scyliorhinus canicula L., the host of L. minor, contains no pigment and the gut contents of L. minor are colourless, but Kearn (1979) found brown pigment (melanin?) in the upper (dorsal) epidermis of the shovel-nosed shark, identified as Aptychotrema banksi (now $A$. rostrata Shaw), and in the gut contents of all adult specimens of the microbothriid $P$. aptychotremae from this host. It seems likely that the gut pigment of $D$. cairae is derived from ingested host epidermis, presumably from the pigmented dorsal surface of this flat elasmobranch. The ventral surfaces of rays are typically unpigmented and, if this is also a feature of the ventrally opening nasal fossae, microbothriids inhabiting these fossae would be expected to lack gut pigment. If this proves to be correct, then all five of our specimens of $D$. cairae most probably came from the host's dorsal surface, despite indications to the contrary on the slide labels.

In monogeneans there is an intimate spatial relationship between the gut and the vitelline follicles. This is to be expected, since vitelline cells are constantly in demand to provide egg-shell material and support for growth and development of embryos (see for example Entobdella soleae (Van Beneden \& Hesse, 1864) Johnston, 1929 in Kearn, 1998). In the absence of a circulatory system, the gut must transport nutrients directly to the metabolically active vitelline follicles. In monogeneans with an extensive vitellarium, this is achieved by branching of the gut, but these branches are difficult to trace unless, like D. cairae, they contain gut pigment. This reveals that some gut branches in $D$. cairae invade sites that contain no vitelline follicles, namely the region lateral to the pharynx and prepharynx, the region immediately surrounding the haptor and the part of the reproductive system comprising the testes, coiled vas deferens and possibly the oötype (Figs. 1-3).

The association of the gut diverticula with the male reproductive system is especially interesting. Numerous short, stubby gut branches cover the dorsal surface of each testis (Fig. 2). Soon after leaving the testes the vas deferens is also supplied with short, medially directed gut branches, the anteriormost of which comprises a repeatedly branching group of digitiform diverticula intimately associated with the highly coiled region of the vas deferens (Fig. 2). This relatively compact group of short diverticula, situated just to the left of the oötype, is a conspicuous feature of adult specimens (Fig. 3). The intimate association between the gut diverticula and the testes may reflect the high metabolic demands of spermatogenesis. The association between gut diverticula and the coiled region of the vas deferens where significant quantities of sperm are stored may reflect a continuing high 
metabolic demand by stored sperm. However, the oötype lies close to this conspicuous bunch of diverticula. In the capsalid Entobdella soleae, the oötype is known to undergo vigorous contractions each time an egg is assembled (Kearn, 1985; Tappenden \& Kearn, 1999), and similar oötype activity is likely to occur in all monogeneans, including microbothriids. Energy to maintain this essential activity in $D$. cairae may be supplied by the adjacent gut diverticula.

The infection site of the specimens of $D$. cairae on the host is unclear. As mentioned above, reference has been made to the dorsal body surface and the nasal fossae as possible attachment sites. Confirmation or otherwise of these references is required. Another indication that some microbothriids have colonised the nasal fossae is the record by Price (1938) of the microbothriid Dermophthirius carcharhini in the olfactory organs (= nasal fossae) of a shark.

The hookless haptors of microbothriids attach themselves by cement to the surface of a single denticle. The preferred site for Dermopristis paradoxus was the skin around the mouth and nasal fossae, and others occurred inside the mouth cavity and on the dorsal skin, but none was collected from inside the nasal fossae (Kearn et al., 2010). In all specimens of $D$. paradoxus studied by Kearn et al. (2010), a detached denticle was found lodged in the haptor, indicating that the bond between haptor and denticle is stronger than the bond between the denticle root and the host's skin. No denticles were found embedded in the haptors of the D. cairae specimens. This may reflect the fact that the bond between the parasites and host denticles is so weakened by freshwater treatment that adhesion is entirely lost and the parasites detach during treatment. However, the haptors of some of the dead parasites may still adhere weakly to the denticles and require dislodgement by the observer. As stated above, notes made at the time of collection do not clarify this.

According to Abel et al. (2010), nasal fossae of elasmobranchs with an active life-style are almost completely filled with wing-shaped folds or lamellae arranged in two rows side by side. Each fossa of $G$. typus contains similar lamellae (Fig. 5) and is separated into incurrent and excurrent passages by flaps, one large and the other small, projecting from the posterior and anterior borders of the fossa, respectively. The lamellae contain no denticles and seem unlikely substrates for the attachment of microbothriids. However, we have determined that an extensive field of closely packed denticles is situated on the inner surface of each large flap (Fig. 5) and a smaller area of scattered denticles lies on the inner surface of the fossa adjacent to the small flap. Therefore, the parasite would be able to cement its haptor to one of the nasal fossa denticles, as it does on the general body skin. In addition to the seclusion gained by this colonisation, the parasite would have the added advantage of ventilation by the olfactory water current. No monogeneans were found inside the nasal fossae of two rays from Heron Island, and fresh material is required to confirm that $D$. cairae attaches itself to denticles inside or close to the nasal fossae.

Acknowledgement We thank Prof. Janine Caira (University of Connecticut, USA), Dr Kirsten Jensen (University of Kansas, USA) and Mr Lyle Squire (Cairns Marine, Cairns, Queensland, Australia) for screening the host elasmobranch in June, 2001 by freshwater bathing.

\section{References}

Abel, R. L., Maclaine, J. S., Cotton, R., Bui Xuan, V., Nickels, T. B., Clark, T. H., Wang, Z., \& Cox, J. P. L. (2010). Functional morphology of the nasal region of a hammerhead shark. Comparative Biochemistry and Physiology, Part A, 155, 464-475.

Beverley-Burton, M., Klassen, G. J., \& Lester, R. J. G. (1987). Generic diagnosis of Asthenocotyle Robinson, 1961 (Monogenea: Microbothriidae) and description of Asthenocotyle taranakiensis new species from Oxynotus brunensis (Oxynotidae) taken in New Zealand waters. International Journal for Parasitology, 17, 965-969.

Glennon, V., Chisholm, L. A., \& Whittington, I. D. (2006). Pseudoleptobothrium aptychotremae Young, 1967 (Monogenea, Microbothriidae) redescribed from a new host, Trygonorrhina fasciata (Rhinobatidae) in South Australia with a description of the larva and post-larval development. Acta Parasitologica, 51, 40-46.

Kearn, G. C. (1965). The biology of Leptocotyle minor, a skin parasite of the dogfish, Scyliorhinus canicula. Parasitology, 55, 473-480.

Kearn, G. C. (1979). Studies on gut pigment in skin-parasitic monogeneans, with special reference to the monocotylid Dendromonocotyle kuhlii. International Journal for Parasitology, 9, 545-552.

Kearn, G. C. (1985). Observations on egg production in the monogenean Entobdella soleae. International Journal for Parasitology, 15, 187-194. 
Kearn, G. C. (1998). Parasitism and the Platyhelminthes. London: Chapman \& Hall, 544 pp.

Kearn, G. C., Evans-Gowing, R., \& Rees, J. (2001). An ultrastructural study of the haptor of the microbothriid monogenean Leptocotyle minor from the skin of the dogfish Scyliorhinus canicula (Scyliorhinidae). Acta Parasitologica, 46, 254-260.

Kearn, G. C., Whittington, I. D., \& Evans-Gowing, R. (2010). A new genus and new species of microbothriid monogenean (Platyhelminthes) with a functionally enigmatic reproductive system, parasitic on the skin and mouth lining of the largetooth sawfish, Pristis microdon, in Australia. Acta Parasitologica, 55, 115-122.

Perkins, E. M., Donnellan, S. C., Bertozzi, T., Chisholm, L. A., \& Whittington, I. D. (2009). Looks can deceive: molecular phylogeny of a family of flatworm ectoparasites (Monogenea: Capsalidae) does not reflect current morphological classification. Molecular Phylogenetics \& Evolution, 52, 705-714.
Price, E. W. (1938). North American monogenetic trematodes II. The families Monocotylidae, Microbothriidae, Acanthocotylidae and Udonellidae (Capsaloidea). Journal of the Washington Academy of Sciences, 28, 183-198.

Sproston, N. G. (1946). A synopsis of the monogenetic trematodes. Transactions of the Zoological Society of London, 25, 185-600.

Tappenden, T., \& Kearn, G. C. (1999). An experimental study of egg assembly in the monogenean (platyhelminth) skin parasite Entobdella soleae, using a fast preservation technique and transmission electron microscopy. Acta Parasitologica, 44, 51-62.

Whittington, I. D., \& Chisholm, L. A. (2008). Diseases caused by Monogenea. In: Eiras, J. C., Segner, H., Wahli, T., \& Kapoor, B. G. (Eds.), Fish diseases. Enfield (NH), USA: Science Publishers, pp. 683-816. 